\title{
A novel case of neonatal acute respiratory distress syndrome with SARS-CoV-2 infection: potential perinatal transmission
}

\author{
Ezgi Yangin Ergon, M.D. ${ }^{a}$, Sinem Akbay, M.D. ${ }^{a}$, Gokce Aytemiz, M.D. ${ }^{b}$, Esma C. Avcl Çelik, M.D. ${ }^{b}$, \\ Arzu Çalıskan Polat, M.D. ${ }^{b}$, Zuhal Umit, M.D. ${ }^{c}$ and Sebnem Paytoncu, M.D. ${ }^{d}$
}

\begin{abstract}
Coronavirus disease 2019 (COVID-19), caused by the severe acute respiratory syndrome coronavirus 2 (SARS-CoV-2), is the first pandemic of the $21^{\text {st }}$ century. SARS-CoV-2 infection is mainly transmitted via droplets. Although some cases of perinatal transmission have been reported, it is unclear whether these infections occurred via transplacental or transcervical routes or via environmental exposure.

Herein, we present the case of a newborn who died with neonatal acute respiratory distress syndrome exhibiting severe pulmonary involvement. The baby was born to a COVID-19 PCR (+) mother by C-section and was found to be COVID-19 PCR (+) from a nasopharyngeal swab sample tested within 24 hours of birth due to the suspected transplacental transmission of SARS-CoV-2 from the mother to the fetus.

Key words: Infant newborn, COVID-19, SARS-CoV-2, placenta, infectious disease transmission, vertical.
\end{abstract}

http: / / dx.doi.org/10.5546/ aap.2021.eng.e531

To cite: Yangin Ergon E, Akbay S, Aytemiz G, Avcı Çelik CE, et al. A novel case of neonatal acute respiratory distress syndrome with SARSCoV-2 infection: potential perinatal transmission. Arch Argent Pediatr 2021;119(5):e531-e535.

\section{INTRODUCTION}

Coronavirus disease 2019 (COVID-19), caused by the severe acute respiratory syndrome coronavirus 2 (SARS-CoV-2), is a novel disease that is transmitted via droplets. Since December 2019, the infection has been spreading worldwide. ${ }^{1}$

a. Department of Neonatology.

b. Department of Pediatrics.

c. Department of Child Infection.

d. Department of Child Cardiology.

Manisa City Hospital, Turkey.

E-mail address:

Ezgi Yangin Ergon, MD: yanginezgi@yahoo.com

Funding: None.

Conflict of interest: None.

Received: 12-17-2020

Accepted: 4-13-2021
When SARS-CoV-2 was first detected, there was no evidence of vertical transmission from mother to fetus. ${ }^{2}$ However, it is unclear whether these occurred via transplacental or transcervical routes or via environmental exposure. ${ }^{3}$ To the best of our knowledge, there are two publications in the existing literature that effectively prove the vertical transmission. ${ }^{4}$

The case presented here is that of a newborn with severe pulmonary involvement. His mother was infected with COVID-19, and the baby was found to be COVID-19(+) within 24 hours of birth with suspected transplacental transmission of SARS-CoV-2.

\section{CASE:}

A male baby born weighing 2460 grams at 34 weeks of gestation, to a 34-year-old COVID-19(+) mother with fever $(+)$, thrombocytopenia and lymphopenia(+), and chest CT scan consistent with bilateral COVID-19 pneumonia. He was delivered by emergency C-section because of maternal vaginal bleeding and placed on nasal continuous positive airway pressure (NCPAP) with $\mathrm{FiO}_{2} 30 \%$. He was then monitored in an isolated negative pressure room. The Apgar score on $1^{\text {st }}$ and $5^{\text {th }}$ minutes was $4 / 7$. The heart rate was $140 / \mathrm{min}$; blood pressure(BP) was 64/33 (37) $\mathrm{mmHg}$; respiratory rate was 64/ min; and $\mathrm{SpO}_{2}$ was $96 \%$ under NCPAP at $30^{\text {th }}$ $\mathrm{min}$. His liver function tests were normal, and acute phase reactants (AFRs) were negative at $6^{\text {th }}$ hour of life. However there was a borderline lymphopenia and thrombocytopenia (Table 1). TORCH serology was normal and direct Coombs was negative. D-dimer was $6.59 \mu \mathrm{g} / \mathrm{mL}$. A thrombosis panel was found to be normal. Chest $X$-ray revealed bilateral ground-glass opacities (Figure 1). Since congenital pneumonia could not be ruled out, ampicillin and gentamicin was initiated. Due to the maternal COVID-19 posivitiy, a nasal swab sample was obtained from the baby (post cleaning following birth) twice at 24-hour intervals. The results of this test revealed that the baby was also COVID-19(+). ${ }^{5}$ As the $\mathrm{FiO}_{2}$ requirement continued to be $>40 \%$ 
despite respiratory support, the patient was administered a surfactant (Curosurf, Chiesi, USA) by the INSURE (intubation-surfactant-extubation) method. However, on $2^{\text {nd }} d a y$, he was intubated and provided with mechanical ventilation $(\mathrm{A} / \mathrm{C}$ mode, PIP: $22 \mathrm{cmH}_{2} \mathrm{O}$, PEEP: $5 \mathrm{cmH}_{2} \mathrm{O}$, frequency: 40, insp. time: $0.35, \mathrm{FiO}_{2} 40 \%$, Heinen Löwenstein Leoni plus) due to tachypnea, intercostal and subcostal retractions, despite the nasal ventilation support. A second dose of the surfactant was administered. The echocardiogram $(\mathrm{ECHO})$ was reported to be normal. On $3^{\text {rd }}$ day, AFRs became positive. The concentration of ampicillin was increased, cefotaxime and azithromycin were added.

On 5th day, the patient, exhibited an increased need for ventilator support and oxygen supply. A third dose of the surfactant was administered. COVID-19 IgM and IgG serology tests were positive. The patient exhibited increased
AFRs, more profound thrombocytopenia, and pronounced lymphopenia (Table 1). Vancomycin and meropenem were initiated for the possibility of nosocomial sepsis. Furthermore, the patient and her mother had thrombocytopenia; neonatal alloimmun thrombocytopenia could not be ruled out, therefore intravenous immunoglobulin was administered.

On $7^{\text {th }}$ day, the patient had high pressure requirement in conventional mechanical ventilation [PIP $27 \mathrm{cmH}_{2} \mathrm{O}$ and Mean Airway Pressure (MAP) $\left.12 \mathrm{cmH}_{2} \mathrm{O}\right]$. He was placed on high-frequency ventilation (HFOV) (MAP $14 \mathrm{cmH}_{2} \mathrm{O}$, frequency 10, amplitude 30, and $\mathrm{FiO}_{2} 80 \%$ ) (Figure 2). During follow-up, HFOV support was gradually increased. Two more surfactant therapies were administered due to secondary surfactant breakdown. Meanwhile, severe pulmonary hypertension $(\mathrm{PH})$ was observed on ECHO. Dopamine, dobutamine

TABLE 1. Laboratory findings of the newborn

\begin{tabular}{|c|c|c|c|c|c|c|}
\hline & Day 1 & Day 3 & Day 5 & Day 8 & Day 11 & Day 17 \\
\hline \multicolumn{7}{|l|}{ Blood count } \\
\hline $\operatorname{WBC}\left(/ \mathrm{mm}^{3}\right)$ & 11400 & 6600 & 4300 & 3700 & 7000 & \\
\hline Lymphocyte $\left(/ \mathrm{mm}^{3}\right)$ & 1420 & 1320 & 500 & 1340 & 1440 & \\
\hline Neutrophil $\left(/ \mathrm{mm}^{3}\right)$ & 8760 & 4260 & 3110 & 1800 & 4930 & \\
\hline Platelet $\left(/ \mathrm{mm}^{3}\right)$ & 73000 & 71000 & 70000 & 65000 & 82000 & \\
\hline $\operatorname{RBC}\left(10^{3} / \mathrm{mm}^{3}\right)$ & 5360 & 4950 & 3620 & 3480 & 4430 & \\
\hline $\mathrm{Hb}(\mathrm{g} / \mathrm{dL})$ & 19 & 17.6 & 13 & 11 & 14.2 & \\
\hline Htc $(\%)$ & 54 & 51.2 & 39.6 & 34.5 & 41.8 & \\
\hline \multicolumn{7}{|l|}{ Blood biochemistry } \\
\hline AST $(\mathrm{U} / \mathrm{L})$ & 55 & 91 & 95 & 92 & & \\
\hline $\operatorname{ALT}(\mathrm{U} / \mathrm{L})$ & 6 & $<5$ & 6 & 6 & & \\
\hline $\mathrm{CK}(\mathrm{U} / \mathrm{L})$ & 290 & & & 49 & & \\
\hline Troponin I (ng/mL) & & & & 0.3 & & \\
\hline $\mathrm{CRP}(\mathrm{mg} / \mathrm{L})$ & $<5$ & 11.7 & 16.1 & 4.6 & 2.9 & \\
\hline \multicolumn{7}{|l|}{ Coagulation } \\
\hline PZ (sec) & 24.1 & & 17.5 & & & \\
\hline PZ-inR & 1.8 & & 1.29 & & & \\
\hline $\mathrm{aPTZ}(\mathrm{sec})$ & 62.5 & & 47 & & & \\
\hline D-Dimer (ug/mL) & 6.59 & & 5.2 & & & \\
\hline Protein C $(\%)$ & & & 46.8 & & & \\
\hline Protein S $(\%)$ & & & 30.8 & & & \\
\hline Anti-thrombin $3(\mathrm{mg} / \mathrm{dL})$ & & & 30.7 & & & \\
\hline \multicolumn{7}{|l|}{ Culture } \\
\hline Blood & negative & negative & negative & & negative & \\
\hline Urine & & negative & negative & & & \\
\hline Tracheal aspirate & & & negative & & negative & negative \\
\hline \multicolumn{7}{|l|}{ Covid-19 test } \\
\hline Nasal PCR & +++ & +++ & & +++ & +++ & +++ \\
\hline $\operatorname{IgM}$ & & & +++ & & & \\
\hline $\operatorname{IgG}$ & & & +++ & & & \\
\hline
\end{tabular}

WBC: White blood cell, RBC: Red blood cell, Hb: Hemoglobin, Htc: Hematocrit, AST: Aspartate aminotransferase, ALT: Alanine transaminase, CK: Creatine kinase, CRP: C-reactive protein, PZ: prothrombin time,

PZ-inR: PZ-Internationel Normalized Ratio, aPTZ: activated partial thromboplastin time, Nasal PCR: Nasal Polymerase Chain Reaction. 
and sildenafil were started. The oxygenation index of the patient was 25. Despite HFOV and repeated surfactant dose administration, $\mathrm{FiO}_{2}$ requirement continued to increase and the clinical picture started to deteriorate even more rapidly after $6^{\text {th }}$ day. ${ }^{6}$ Inhaled nitric oxide (iNO) was started. $\mathrm{FiO}_{2}$ requirement could be reduced to $65 \%$ with iNO. A lung recruitment maneuver was performed in HFOV for acute

\section{Figure 1. Chest $x$-ray. Nasal ventilation, Day 1}

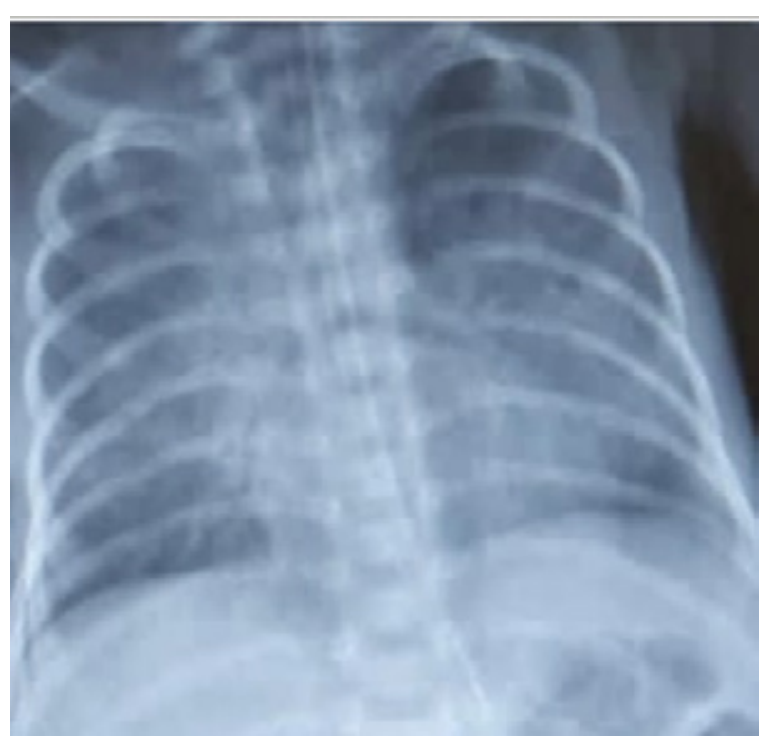

Figure 2. Chest $x$-ray. High frecuency ventilation. Day 7

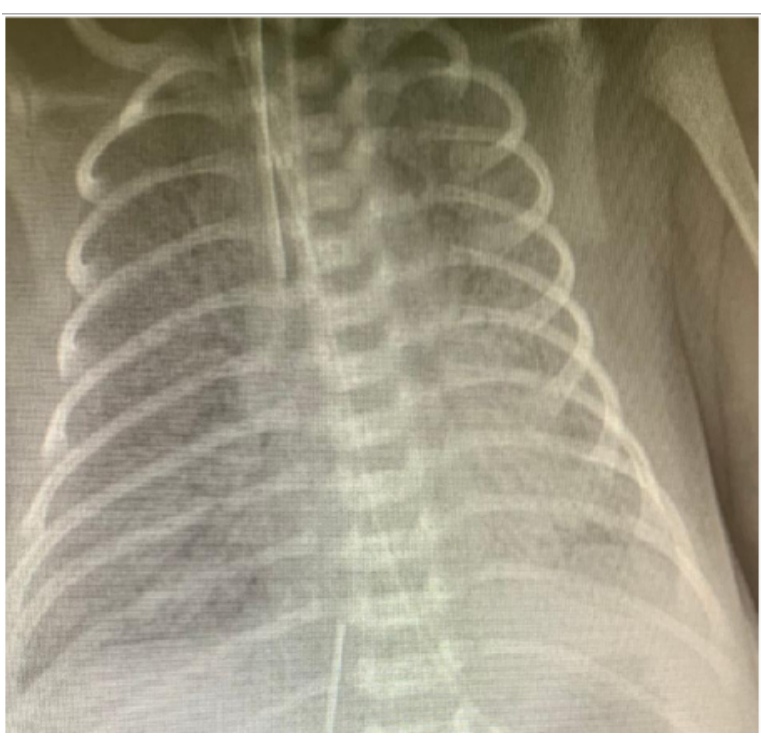

respiratory distress syndrome (ARDS), wherein the MAP value was gradually increased to 30 $\mathrm{cmH}_{2} \mathrm{O}$ (opening pressure) and reduced to 24 $\mathrm{cmH}_{2} \mathrm{O}$ (closing pressure) at 2-3 minute intervals, wherein $26 \mathrm{cmH}_{2} \mathrm{O}$ MAP was used as it was considered the optimal pressure. As a result, the $\mathrm{FiO}_{2}$ requirement could be reduced to a maximum of $55 \%$ (Figure 3). The patient was considered to have severe neonatal ARDS according to the Montreux definition. ${ }^{7}$ Because of his unstable condition, he was considered not eligible for extracorporeal membrane oxygenation and his follow-up continued with the existing available support. Repeated PCR tests using tracheal aspirates for COVID-19 was found to be positive. ${ }^{5}$ On $11^{\text {th }}$ day, although AFRs were negative, he still had lymphopenia and thrombocytopenia, but no bacterial growth in the blood, urine and tracheal aspirate cultures were observed. Lopinavirritonavir was started as an antiviral treatment for COVID-19. The patient, who was intubated under HFOV $+\mathrm{iNO}$ support and had a poor general condition with $90 \% \mathrm{FiO}_{2}$ and $80 \%-85 \% \mathrm{SpO}_{2}$ did not respond to supportive therapy and died on $17^{\text {th }}$ day, unfortunately.

The baby's mother was hospitalized for 3 days following birth and was discharged to receive the rest of her treatment due to the absence of respiratory distress. She became asymptomatic at the end of her 14-day quarantine period and was later found to be PCR-negative for COVID-19.

Figure 3. Chest $x$-ray. High frecuency ventilation + nitric oxide + lung recruitment maneuver. Day 8

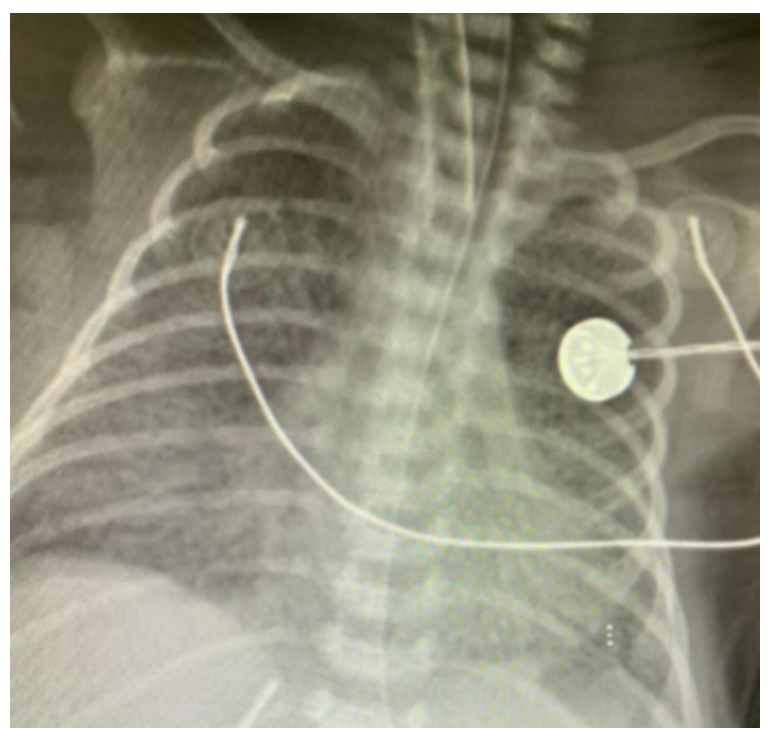




\section{DISCUSSION}

Studies proving the vertical transmission are limited in the existing literature. ${ }^{4}$ Whereas, Shah et al. published a classification that includes the "SARS-CoV-2 case definition" and evaluates the potential perinatal transmission. ${ }^{8}$ According to this, our patient was included in the "neonatal infection acquired intrapartum, confirmed" category. The patient could not be included definitely in the "neonatal congenital infection" category because umbilical cord or amniotic fluid sampling could not be performed. However, a potential perinatal transmission cannot be ruled out as our patient showed symptomatic severe pulmonary involvement and clinical manifestations of SARS-CoV-2 and both the mother and baby were symptomatic with blood test results consistent with COVID-19. It is known that angiotensin converting enzyme 2 (ACE-2) is the target receptor for SARS-CoV-2 and is present abundantly in the placenta. ${ }^{9}$ The level of ACE-2 reaches its peak between the end of pregnancy and the early postnatal (PN) days on the animal studies. ${ }^{9}$ These data confirm the transplacental transmission, especially during the last weeks of pregnancy. Additionally, the fact that neonatal viremia was fatal and more severe than maternal viremia in this study contradicts the concept of viral load, and this may have resulted from the high ACE-2 levels in the placenta observed during the early PN days.

The likelihood of developing severe forms of SARS-CoV-2 is associated with ACE2 expression in some individuals. ${ }^{10}$ The role of estrogen in ACE-2 upregulation and rapid circulation of ACE-2 in children may account for the less severe forms of SARS-CoV-2 infection observed in them. ${ }^{10}$ However, apart from age, gender, and comorbidities, some laboratory risk factors for severe forms of SARS-CoV-2 have also been described. ${ }^{11}$ These are related to hyperinflammation, immunodysregulation, and hypercoagulopathy. In the literature, high levels of ferritin, IL-6, and D-dimer have been reported in cases presenting with such severe clinical symptoms. ${ }^{12}$ Moreover, lymphopenia observed in $72 \%-85 \%$ severe SARS-CoV-2 cases is the hallmark of COVID-19 infection. A reduced lymphocyte count, elevated leukocyte count, and high neutrophil-lymphocyte ratio (NLR) may indicate a severe course of the disease. ${ }^{13}$ In our patient, the gradually decreasing lymphocyte count and increasing NLR, along with the patient's sex, indicated the presence of a severe

\section{SARS-CoV-2 infection.}

It is very difficult to determine whether the respiratory distress was due to SARS-CoV-2 or prematurity in this case. It is also possible that the maternal SARS-CoV-2 was the reason for the emergency $\mathrm{C}$-section and premature birth. The presence of SARS-CoV-2 is supported by the fact that repeated PCR tests for COVID-19 were positive, pronounced lymphopenia coexisted, and respiratory distress increased and became more marked on 15th day. Also, he exhibited severe persistent $\mathrm{PH}$ and neonatal ARDS with a poor response to respiratory support. In the existing literature, only one case of newborn with severe respiratory symptoms and severe pneumonia, similar to our patient, has been reported. ${ }^{14}$

Some studies showed that the genetic variants causing loss of function in X chromosomal TLR7 resulted in severe and fatal SARS-CoV-2 by impairing type 1 and 2 interferon responses. ${ }^{15}$ TLR7 was performed; however, no variation in TLR7 gene exons was detected.

There are still many unanswered questions regarding the severity of the transmitted disease and its existence and time of transmission from the mother to the baby. In this article, we report the case of a newborn patient with fatal neonatal ARDS secondary to neonatal viremia, wherein the presence of a potential perinatal transmission was supported by various aspects. While this case provided the opportunity to address a clinical picture that has not been described often in the literature, it also engendered new questions on neonatal SARS-CoV-2 and its course.

\section{REFERENCES}

1. Huang C, Wang Y, Li X, Zhao J, et al. Clinical features of patients infected with 2019 novel coronavirus in Wuhan, China. Lancet. 2020; 395(10223):497-506.

2. Alserehi H, Wali G, Alshukairi A, Alraddadi B. Impact of Middle East respiratory syndrome coronavirus (MERS$\mathrm{CoV}$ ) on pregnancy and perinatal outcome. BMC Infect Dis. 2016; 16:105.

3. Zamaniyan M, Ebadi A, Aghajanpoor Mir S, Rahmani $Z$, et al. Preterm delivery, maternal death, and vertical transmission in a pregnant woman with COVID-19 infection. Prenat Diagn. 2020; 40(13):1759-61.

4. Patanè L, Morotti D, Giunta MR, Sigismondi C, et al. Vertical transmission of coronavirus disease 2019: severe acute respiratory syndrome coronavirus 2 RNA on the fetal side of the placenta in pregnancies with coronavirus disease 2019-positive mothers and neonates at birth. Am J Obstet Gynecol MFM. 2020; 2(3):100145.

5. Yu XS, Sun S, Shi Y, Wang H, et al. SARSCoV-2 viral load in sputum correlates with risk of COVID-19 progression. Crit Care. 2020; 24(1):170.

6. Bollaga WB, Gonzales JN. Phosphatidylglycerol and surfactant: A potential treatment for COVID-19? Med Hypotheses. 2020; 144:110277. 
7. De Luca D, van Kaam AH, Tingay DG, Courtney SE, et al. The Montreux definition of neonatal ARDS: biological and clinical background behind the description of a new entity. Lancet Respir Med. 2017; 5(8):657-66.

8. Shah PS, Diambomba Y, Acharya G, Morris SK, et al. Classification system and case definition for SARS-CoV-2 infection in pregnant women, fetuses, and neonates. Acta Obstet Gynecol Scand. 2020; 99(5):565-8.

9. Li M, Chen L, Zhang J, Xiong C, et al. The SARS-CoV-2 receptor ACE2 expression of maternal-fetal interface and fetal organs by single-cell transcriptome study. PloS One. 2020; 15(4):e0230295.

10. Da Silva JS, Gabriel-Costa D, Wang H, Ahmad S, et al. Blunting of cardioprotective actions of estrogen in female rodent heart linked to altered expression of cardiac tissue chymase and ACE2. J Renin Angiotensin Aldosterone Syst. 2017; 18(3):1470320317722270.
11. Chen G, Wu D, Guo W, Cao Y, et al. Clinical and immunologic features in severe and moderate coronavirus disease 2019. J Clin Invest. 2020; 130(5):2620-9.

12. Kermali M, Khalsa RK, Pillai K, Ismail Z, et al. The role of biomarkers in diagnosis of COVID-19-A systematic review. Life Sci. 2020; 254:117788.

13. Wang F, Nie J, Wang H, Zhao Q, et al. Characteristics of peripheral lymphocyte subset alteration in COVID-19 pneumonia. J Infect Dis. 2020; 221(11):1762-9.

14. Algadeeb KB AlMousa HH, AlKadhem SM, Alduhilan II $\mathrm{MO}$, et al. A Novel Case of Severe Respiratory Symptoms and Persistent Pulmonary Hypertension in a Saudi Neonate With SARS-CoV-2 Infection. Cureus. 2020; 12(9):e10472.

15. van der Made CI, Simons A, Schuurs-Hoeijmakers J, van der Heuvel G, et al. Presence of genetic variants among young men with severe COVID-19. JAMA. 2020; 324(7):111. 